\title{
Hydrogen Sulfide Improves Endothelial Dysfunction via Downregulating BMP4/COX-2 Pathway in Rats with Hypertension
}

\author{
Lin Xiao, ${ }^{1,2}$ Jing-Hui Dong, ${ }^{1}$ Sheng Jin, ${ }^{1}$ Hong-Mei Xue, ${ }^{1,2}$ \\ Qi Guo, ${ }^{1} \mathrm{Xu}$ Teng, ${ }^{1,2}$ and Yu-Ming $\mathrm{Wu}^{1,3,4}$ \\ ${ }^{1}$ Department of Physiology, Hebei Medical University, Shijiazhuang 050017, China \\ ${ }^{2}$ Hebei Key Laboratory of Animal Science, Hebei Medical University, Shijiazhuang 050017, China \\ ${ }^{3}$ Hebei Collaborative Innovation Center for Cardio-Cerebrovascular Disease, Shijiazhuang 050017, China \\ ${ }^{4}$ Key Laboratory of Vascular Medicine of Hebei Province, Shijiazhuang 050017, China \\ Correspondence should be addressed to Yu-Ming Wu; wuyum@yahoo.com
}

Received 28 April 2016; Accepted 26 June 2016

Academic Editor: Guangdong Yang

Copyright (C) 2016 Lin Xiao et al. This is an open access article distributed under the Creative Commons Attribution License, which permits unrestricted use, distribution, and reproduction in any medium, provided the original work is properly cited.

\begin{abstract}
Aims. We object to elucidate that protective effect of $\mathrm{H}_{2} \mathrm{~S}$ on endothelium is mediated by downregulating BMP4 (bone morphogenetic protein 4)/cyclooxygenase- (COX-) 2 pathway in rats with hypertension. Methods and Results. The hypertensive rat model induced by two-kidney one-clip (2K1C) model was used. Exogenous NaHS administration $(56 \mu \mathrm{mol} / \mathrm{kg} /$ day, intraperitoneally once a day) reduced mean arterial pressure (MAP) of $2 \mathrm{K1C}$ rats from $199.9 \pm 3.312 \mathrm{mmHg}$ to $159.4 \pm 5.434 \mathrm{mmHg}$, while NaHS did not affect the blood pressure in the Sham rats and ameliorated endothelium-dependent contractions (EDCs) of renal artery in 2K1C rats. $2 \mathrm{~K} 1 \mathrm{C}$ reduced CSE level twofold, decreased plasma levels of $\mathrm{H}_{2} \mathrm{~S}$ about 6-fold, increased BMP4, Nox2, and Nox4 levels 2 fold and increased markers of oxidative stress MDA and nitrotyrosine 1.5-fold, upregulated the expression of phosphorylation-p38 MAPK 2-fold, and increased protein levels of COX-2 1.5-fold, which were abolished by NaHS treatment. Conclusions. Our results demonstrate that $\mathrm{H}_{2} \mathrm{~S}$ prevents activation of BMP4/COX-2 pathway in hypertension, which may be involved in the ameliorative effect of $\mathrm{H}_{2} \mathrm{~S}$ on endothelial impairment. These results throw light on endothelial protective effect of $\mathrm{H}_{2} \mathrm{~S}$ and provide new target for prevention and therapy of hypertension.
\end{abstract}

\section{Introduction}

Hydrogen sulfide $\left(\mathrm{H}_{2} \mathrm{~S}\right)$ has been proved to be the third endogenous gasotransmitter following nitric oxide (NO) and carbon oxide (CO). $\mathrm{H}_{2} \mathrm{~S}$ is endogenously produced from $\mathrm{L}$ cysteine by two pyridoxal- $5^{\prime}$-phosphate-dependent enzymes, that is, cystathionine $\beta$-synthase (CBS) and cystathionine $\gamma$ lyase (CSE) in mammalian tissues [1]. Recently, it was found that another mitochondrial enzyme, 3-mercaptopyruvate sulfurtransferase (3-MST) in conjunction with cysteine aminotransferase (CAT), contributes significantly in generating $\mathrm{H}_{2} \mathrm{~S}$ from L-cysteine in the presence of $\alpha$-ketoglutarate [2]. The expression of those three enzymes is tissue-specific, and, in blood vessels, CSE is a major $\mathrm{H}_{2} \mathrm{~S}$-producing enzyme expressed in both smooth muscle and endothelium [3-5]. $\mathrm{H}_{2} \mathrm{~S}$ is endowed with biological and physiological functions in cardiovascular system. $\mathrm{H}_{2} \mathrm{~S}$ has been well known as a vasodilator and plays an integral role in the homeostatic regulation of blood pressure [6].

Endothelial dysfunction is an initial factor in the pathogenesis of various vascular diseases such as atherosclerosis and hypertension. A number of studies have showed that $\mathrm{H}_{2} \mathrm{~S}$ played endothelium protection through decreasing the level of oxidative stress [7-10], strengthening endothelial NO production via activating eNOS Ser 1177 phosphorylation [11], and inhibiting inflammation of endothelium, which 
resulted in ameliorating the development of hypertension [12]. However, the exact mechanism of $\mathrm{H}_{2} \mathrm{~S}$ remains to be fully clarified.

Bone morphogenetic protein 4 (BMP4) is one of the BMP family from BMP2 to BMP7, which belongs to TGF$\beta$ superfamily [13]. Original studies showed that BMP4 was bound to BMP receptors containing type I and type II [14] and then regulated physiological and pathological process of embryonic development, bone, and cartilage formation [1517]. Several studies have further implied that BMP4 might be involved in exaggerating cardiac ischemia-reperfusion injury [18] and atherosclerotic calcification plaques [19]. Activating vascular BMP4 can promote vascular calcification in hyperglycemia and diabetes [20]. BMP4 infused chronically results in hypertension and is considered as a novel mediator of endothelial dysfunction and hypertension [21]. Endothelial dysfunction can be ameliorated via inhibiting BMP4 cascade [22].

As a proinflammatory gene, BMP4 induces endothelium dysfunction in systemic circulation and resulted in not only impairment of vascular relaxation [23] but also exaggeration of vascular contraction. BMP4 binds to BMP4 receptor which activates NADPH oxidase and then chronically increased the expression of cyclooxygenase- (COX-) 2 through p38 MAPKdependent mechanism. COX-2 contributes to production of constrictive prostaglandins followed by impairing endothelial function and exacerbating endothelium-dependent contractions (EDCs) [24].

Our previous results found that $\mathrm{H}_{2} \mathrm{~S}$ lowered blood pressure and improved endothelial function [25]. However, the detailed mechanism of ameliorative effect of $\mathrm{H}_{2} \mathrm{~S}$ on impaired endothelial function in hypertension still remained underlying. Therefore, we hypothesize that $\mathrm{H}_{2} \mathrm{~S}$ can downregulate BMP4/COX-2 pathway, which may be involved in ameliorating endothelial dysfunction in hypertension. Here, the rat model of hypertension resulting from two-kidney oneclip (2K1C) model is used to verify the effect of $\mathrm{H}_{2} \mathrm{~S}$ on BMP4/COX-2 pathway and EDCs in renal artery.

\section{Methods}

2.1. Agents. NaHS, ACh, and L-NAME were purchased from Sigma-Aldrich Chemical (St. Louis, MO, United States). ACh and $L$-NAME were dissolved in distilled water.

2.2. Preparation of Hypertensive Model in Rats. 7-weekold male Sprague-Dawley rats were obtained from Animal Research Center of Hebei Medical University, which were kept in ordinary cages at room temperature of $25 \pm 3^{\circ} \mathrm{C}$ with $12 \mathrm{~h}$ dark/light cycles (lights on 6:00) with food and water ad libitum. All animal procedures were complied with the Animal Management Rule of the Ministry of Health, People's Republic of China (documentation number 55, 2001), and the Care and Use of Laboratory Animals published by the US National Institutes of Health (NIH Publication number 85-23, revised in 1996) and approved by the Animal Care Committee of Hebei Medical University.
The rats were randomly divided into 4 groups $(n=6)$ : Sham, Sham $+\mathrm{NaHS}, 2 \mathrm{~K} 1 \mathrm{C}$, and $2 \mathrm{~K} 1 \mathrm{C}+\mathrm{NaHS}$. The rats in $2 \mathrm{~K} 1 \mathrm{C}$ and $2 \mathrm{~K} 1 \mathrm{C}+\mathrm{NaHS}$ group were anesthetized with intraperitoneal injections of pentobarbital sodium (30 mg/kg) and then were subjected to unilateral clipping of the renal artery to establish $2 \mathrm{~K} 1 \mathrm{C}$ model. In brief, a left kidney was exposed via laparotomy and then the left renal artery was carefully separated from the left renal vein and connected tissues. In the $2 \mathrm{~K} 1 \mathrm{C}$ and $2 \mathrm{~K} 1 \mathrm{C}+\mathrm{NaHS}$ groups, the left renal artery was clipped by a rigid U-shaped solid silver clip with an open slit of $0.25 \mathrm{~mm}$, resulting in partial occlusion of renal perfusion. The contralateral kidney was left untouched. Sham and Sham + NaHS groups underwent the same procedure, but kidneys were only mobilized and renal vessels were only separated instead of being partially ligated. The rats were kept in cages after surgery for three weeks until blood pressure was stable; Sham + NaHS and $2 \mathrm{~K} 1 \mathrm{C}+\mathrm{NaHS}$ groups received $\mathrm{NaHS} 56 \mu \mathrm{mol} / \mathrm{kg} /$ day intraperitoneally from the fourth week after the surgery which maintained for 20 weeks. Sham and $2 \mathrm{~K} 1 \mathrm{C}$ groups received saline as vehicle.

2.3. Mean Arterial Pressure Measurement. Mean arterial pressure (MAP) was measured noninvasively by tail-cuff plethysmography (BP-100A, Chengdu Taimeng Software CO. Ltd., Chengdu, China) after the rats were stabilized and remained quiescent. Briefly, MAP was measured before and further at every four weeks after surgery for 20 weeks. MAP measurement was always conducted between 9:00 and 12:00 $\mathrm{AM}$ and an average of 3 consecutive readings was taken as the systolic blood pressure of each rat.

2.4. Blood Vessel Preparation. Adult male rats were euthanized by $\mathrm{CO}_{2}$ suffocation and rat intralobar renal arteries were dissected and placed in ice-cold Krebs solution (mmol/L): $119 \mathrm{NaCl}, 4.7 \mathrm{KCl}, 2.5 \mathrm{CaCl}_{2}, 1 \mathrm{MgCl}_{2}, 25 \mathrm{NaHCO}_{3}$, $1.2 \mathrm{KH}_{2} \mathrm{PO}_{4}$, and $11 \mathrm{D}$-glucose, which gassed by $95 \% \mathrm{O}_{2} / 5 \%$ $\mathrm{CO}_{2}$ at $37^{\circ} \mathrm{C}(\mathrm{pH} \sim 7.4)$. The arteries were carefully cleaned of adhering adipose tissue and cut into ring segments $2 \mathrm{~mm}$ in length for functional studies. Rings were suspended in a myograph (620 M, Danish MyoTechnology, Aarhus, Denmark) for recording of changes in isometric tension. Briefly, 2 stainless steel wires ( $40 \mu \mathrm{m}$ in diameter) were put through the lumen of the vessel, and each wire was fixed to the jaws built in the myograph. The organ chamber was filled with $5 \mathrm{~mL}$ of Krebs solution. Each ring was stretched to an optimal tension of $2.5 \mathrm{mN}$ and then allowed to stabilize for 60 minutes before the start of each experiment.

2.5. Endothelial Functional Studies. The series of experiments examined the alterations in EDCs. Firstly, renal artery rings were treated for 30 minutes with $100 \mu \mathrm{mol} / \mathrm{L}$ L-NAME to eliminate the interference of endothelium-derived nitric oxide (NO), a procedure commonly adopted to uncover ACh-induced EDCs [26, 27], and then contractions were elicited by Ach $(0.03-100 \mu \mathrm{mol} / \mathrm{L})$. Vasocontraction was determined in relative values as the percentage of $60 \mathrm{mmol} / \mathrm{L}$ $\mathrm{KCl}$ contraction. 
2.6. Measurement of $\mathrm{H}_{2} \mathrm{~S}$ Content. $\mathrm{H}_{2} \mathrm{~S}$ levels in plasma were measured as described in previous experiment [28]. Briefly, $30 \mu \mathrm{L}$ plasma was used to detect $\mathrm{H}_{2} \mathrm{~S}$. $\mathrm{H}_{2} \mathrm{~S}$ concentrations were determined using a curve generated with sodium sulfide $(0-40 \mu \mathrm{mol} / \mathrm{L})$ standards, and the $\mathrm{H}_{2} \mathrm{~S}$ concentration in plasma was expressed as $\mu \mathrm{mol} / \mathrm{L}$.

2.7. Western Blot Analysis. Renal arteries from four groups were homogenized in ice-cold RIPA lysis buffer $(1 \mu \mathrm{g} / \mathrm{mL}$ leupeptin, $5 \mu \mathrm{g} / \mathrm{mL}$ aprotinin, $100 \mu \mathrm{g} / \mathrm{mL}$ PMSF, $1 \mathrm{mmol} / \mathrm{L}$ sodium orthovanadate, $1 \mathrm{mmol} / \mathrm{L}$ EGTA, $1 \mathrm{mmol} / \mathrm{L}$ EDTA, $1 \mathrm{mmol} / \mathrm{L} \mathrm{NaF}$, and $2 \mathrm{mg} / \mathrm{mL} \quad \beta$-glycerophosphate). The homogenates were incubated on ice for 20 minutes and then centrifuged at $20000 \times \mathrm{g}$ for 20 minutes at $4^{\circ} \mathrm{C}$. The supernatant was collected and the protein concentration was determined using the bicinchoninic acid (BCA) method (Generay biotechnology, Shanghai, China). Equal amounts of protein samples were electrophoresed through a 7.5\% SDSpolyacrylamide gel and then transferred onto immobilon$\mathrm{P}$ polyvinylidene difluoride (PVDF) membrane (Millipore) using wet transfer at $100 \mathrm{~V}$ for 90 minutes at $4^{\circ} \mathrm{C}$. Nonspecific binding sites were blocked by $5 \%$ nonfat milk or $1 \%$ BSA in $0.05 \%$ Tween-20 Tris-buffered saline (TBST) and then incubated overnight at $4^{\circ} \mathrm{C}$ with primary antibodies, anti-AT1R (1:1000, Abcam), anti-BMP4 (1:500, Sigma), anti-Nox2 (1:1000, Abcam), anti-Nox4 (1:1000, proteintech), antip6 $7^{\text {phox }}(1: 1000$, EPITOMICS), anti-Nitrotyrosine $(1: 1000$, MILLIPORE), COX-2 (1:1000, Cayman), CSE (1:1000, Proteintech), and p38 MAPK, phospho-p38 MAPK (1:1000, Wanleibio). The blots were incubated with appropriate secondary antibodies with a horseradish peroxidase- (HRP-) conjugated goat anti-rabbit antibody (Proteintech, Chicago, United States) or HRP-conjugated rabbit anti-goat antibody (Proteintech, Chicago, United States) at 1:3000 dilution for 1 hour at room temperature. All blots washes were performed in TBST. Blots were developed with an enhanced chemiluminescence detection system (Sagecreation, Beijing, China). Densitometry was performed using lane-1 system (Sagecreation, Beijing, China).

2.8. Measurement of Malondialdehyde (MDA) Concentration. MDA concentration in plasma was measured by using thiobarbituric acid reactive substances (TBARS) assay kit (Nanjing Jiancheng Bioengineering Institute, Nanjing, Jiangsu, China) according to the instruction of manufacturer. The plasma was mixed with working solution, followed by 40 minute incubation in a boiling water bath. The mixed solution was centrifuged at $3500 \mathrm{rpm}$ for 10 minutes. The absorbance of the supernatant $(532 \mathrm{~nm})$ was measured. The results were expressed as $\mathrm{nmol} / \mathrm{mL}$.

2.9. Statistical Analysis. Data are represented as means \pm SEM. $E_{\max }$ denotes the maximal response produced by the constrictor or dilator. Statistical significance was determined by one-way analysis of variance (ANOVA) followed by Bonferroni post hoc tests (GraphPad Software, San Diego, United States). $P$ values less than 0.05 indicate statistical significance.

\section{Result}

3.1. Exogenous Administration of NaHS Lowered Blood Pressure and Ameliorated EDCs in Renal Artery in Hypertensive Rats. In $2 \mathrm{~K} 1 \mathrm{C}$ rats, NaHS ( $56 \mu \mathrm{mol} / \mathrm{kg} /$ day) treatment for 20 weeks significantly lowered MAP $(159.4 \pm 5.434 \mathrm{mmHg}$ versus $199.9 \pm 3.312 \mathrm{mmHg}, P<0.05)$. MAP in Sham $+\mathrm{NaHS}$ rats had no changes compared with Sham rats $(102.6 \pm 2.687$ versus $102.4 \pm 3.721 \mathrm{mmHg}$ ) (Figure 1(a)). Rings in $2 \mathrm{~K} 1 \mathrm{C}$ rats displayed enhancing EDCs compared with Sham rings $\left(E_{\max }\right.$ : $127.2+3.216 \%$ in $2 \mathrm{~K} 1 \mathrm{C}$ rings, $n=7$ versus $34.68+10.34 \%$ in Sham, $n=5 ; P<0.05)$. Renal arteries from $2 \mathrm{~K} 1 \mathrm{C}+\mathrm{NaHS}$ rats reduced the enhanced EDCs to $72.66+6.007 \%$. Chronically exogenously administrating NaHS had no effect on EDCs in Sham rats (Figure $1(\mathrm{~b})$ ).

3.2. Exogenous Administration of NaHS Improved the Level of Plasma $\mathrm{H}_{2} \mathrm{~S}$ and Renal Artery CSE Protein Expression in Hypertensive Rats. Western blot analysis showed that the protein level of CSE reduced in $2 \mathrm{~K} 1 \mathrm{C}$ rats compared with Sham rats. NaHS treatment in $2 \mathrm{~K} 1 \mathrm{C}$ rats increased the expression of CSE. There is no difference among the Sham, Sham + NaHS, and 2K1C + NaHS groups (Figure 2(a)). The plasma $\mathrm{H}_{2} \mathrm{~S}$ level in $2 \mathrm{~K} 1 \mathrm{C}$ rats was significantly lower than that in Sham rats $(0.28 \pm 0.04$ versus $1.07 \pm 0.08 \mu \mathrm{mol} / \mathrm{L}$, $P<0.05)$. NaHS treatment elevated the plasma $\mathrm{H}_{2} \mathrm{~S}$ level to $0.67 \pm 0.01 \mu \mathrm{mol} / \mathrm{L}(P<0.05)$. There is no difference between Sham and Sham + NaHS group $(1.07 \pm 0.08$ versus $1.24 \pm 0.14 \mu \mathrm{mol} / \mathrm{L}, P>0.05$ ) (Figure 2(b)).

3.3. Exogenous Administration of NaHS Downregulated the Protein Expression of BMP4 in Hypertensive Rats. The Western blot results showed that the protein expression of BMP4 was elevated in hypertensive renal artery. Chronic treatment with NaHS decreased the level of BMP4 in hypertensive rats (Figure 3).

3.4. Exogenous Administration of NaHS Decreased the Level of Oxidative Stress in Hypertensive Rats. The level of oxidative stress as reflected by the expressions of NOX-2, NOX-4, and p $67^{\text {phox }}$ was augmented in $2 \mathrm{~K} 1 \mathrm{C}$ renal arteries. Exogenous treatment with NaHS rectified the overexpression of NOX2 , NOX-4, and p67 $7^{\text {phox }}$ (Figures $4(\mathrm{a})-4(\mathrm{c})$ ). As stable markers of oxidative stress, the level of nitrotyrosine in $2 \mathrm{~K} 1 \mathrm{C}$ arteries was increased and the plasma MDA level in $2 \mathrm{~K} 1 \mathrm{C}$ rats was significantly elevated $(6.779 \pm 0.3518$ versus $4.273 \pm$ $0.1313 \mathrm{nmol} / \mathrm{mL}, P<0.05)$. Treatment with NaHS decreased the arterial protein levels of nitrotyrosine and the plasma level of MDA $(4.947 \pm 0.1649$ versus $6.779 \pm 0.3518 \mathrm{nmol} / \mathrm{mL}$, $P<0.05$ ) (Figures 4(d)-4(e)).

3.5. Exogenous Administration of NaHS Decreased Phosphorylation-p38 MAPK Protein Expression in Hypertensive Rats. The Western blot results showed that the protein expression of the phosphorylation-p38 MAPK was upregulated in 2K1C renal arteries. Chronic treatment with NaHS could alleviate the increasing tendency of phosphorylation-p38 MAPK. 


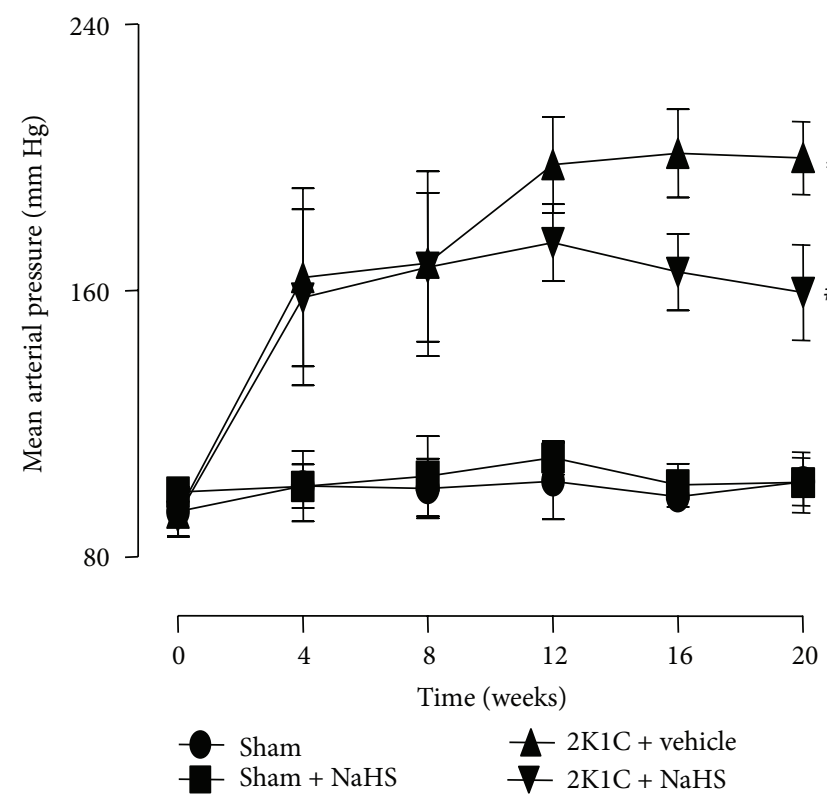

(a)

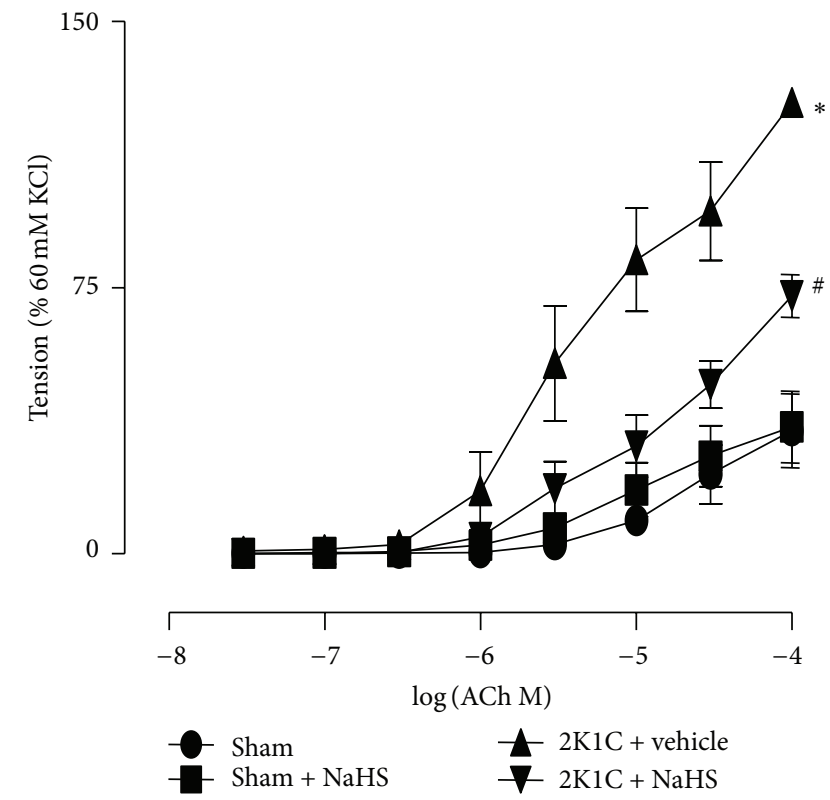

(b)
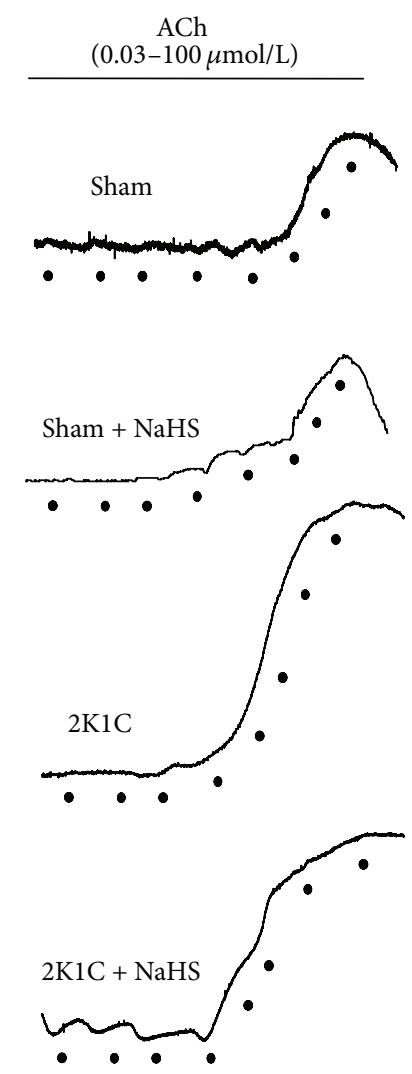

(c)

FIGURE 1: Effect of NaHS on blood pressure and endothelial-dependent renal arterial contraction. (a) Mean arterial pressure (MAP); (b) endothelium-dependent contractions (EDCs) in four groups; (c) original recording of EDCs in four groups. Data are means \pm SEM. ${ }^{*} P<0.05$ versus Sham; ${ }^{\#} P<0.05$ versus $2 \mathrm{~K} 1 \mathrm{C}$ vehicle. $n=10$ in each group for MAP measurement; $n=6$ in each group for EDCs measurement. 


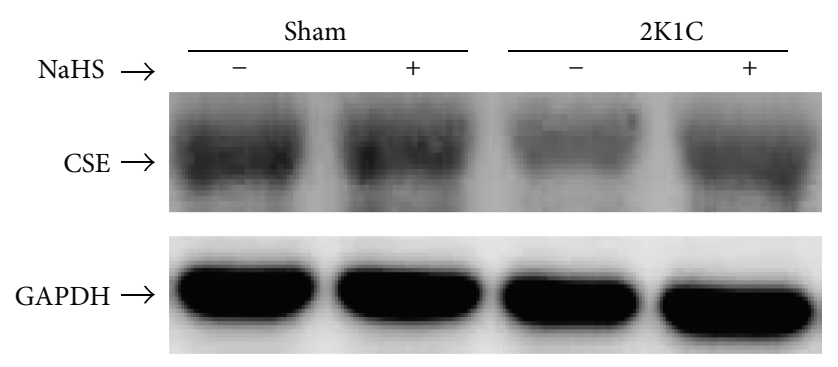

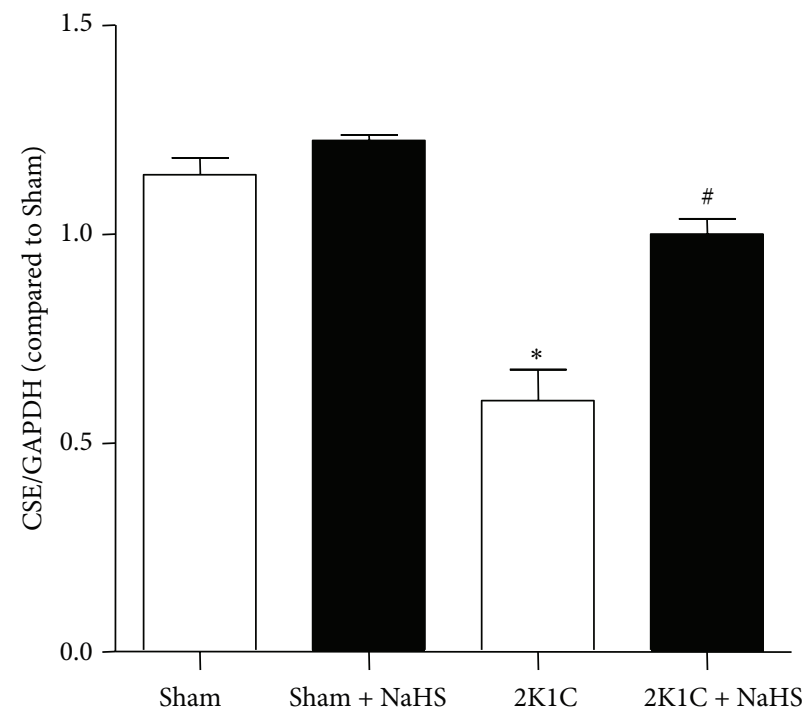

(a)

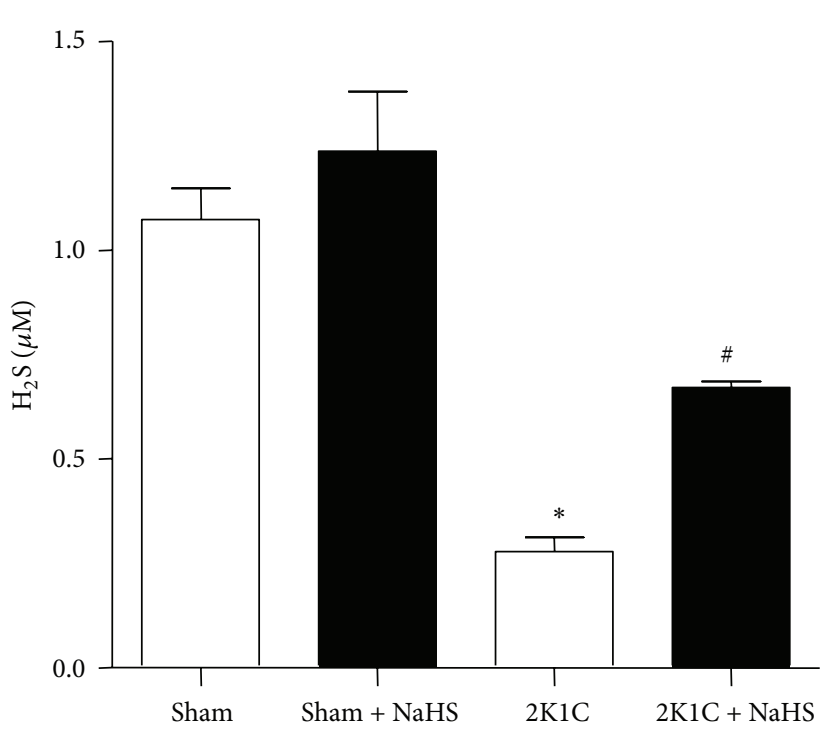

(b)

Figure 2: Effect of NaHS on protein levels of CSE in renal artery and plasma levels of $\mathrm{H}_{2} \mathrm{~S}$. (a) Protein expression of CSE in renal arteries; (b) $\mathrm{H}_{2} \mathrm{~S}$ levels in plasma. Data are means \pm SEM. ${ }^{*} P<0.05$ versus Sham; ${ }^{\#} P<0.05$ versus $2 \mathrm{~K} 1 \mathrm{C}$ vehicle. $n=4$ in each group for Western blotting; $n=10$ in each group for plasma $\mathrm{H}_{2} \mathrm{~S}$ level.

However, there is difference on the total expression of $\mathrm{p} 38$ MAPK among all groups (Figure 5).

\subsection{Exogenous Administration of NaHS Decreased COX-2} Protein Expression in Hypertensive Rats. In renal arteries of $2 \mathrm{~K} 1 \mathrm{C}$ rats, protein expressions of COX-2 were increased compared with that of Sham rats. Chronic administration of $\mathrm{NaHS}$ inhibited the increased expression of COX-2 in $2 \mathrm{~K} 1 \mathrm{C}$ renal arteries (Figure 6).

\section{Discussion}

The present study demonstrates that NaHS reduces MAP and ameliorates EDCs which were both elevated in $2 \mathrm{K1C}$ hypertensive rats. Chronically administrating NaHS plays positive role in upregulating CSE protein expression and increasing the level of $\mathrm{H}_{2} \mathrm{~S}$ in plasma, in which both of them were also reduced in 2K1C hypertensive rats. Moreover, we found that in hypertensive rats the protein levels of BMP4 are increased, and then oxidative stress and p38 MAPK are activated, resulting in upregulation of COX-2, where the pathway contributes to augmentation of EDCs.
Intraperitoneal injection of NaHS interestingly reverses the activation of the above pathway (Figure 7).

Among variety of experimental or genetic models of hypertension, the $2 \mathrm{~K} 1 \mathrm{C}$ hypertensive model is a classical one of renovascular angiotensin-II-dependent hypertension [29]. The $2 \mathrm{~K} 1 \mathrm{C}$ rats represent transient activation of reninangiotensin system (RAS) and thereafter sustained rise in blood pressure [30]. This model is used widely to investigate hypertension. Previous study shows that endogenous cystathionine- $\gamma$-lyase (CSE) $/ \mathrm{H}_{2} \mathrm{~S}$ pathway exited in vessels [31]. In hypoxia-induced pulmonary hypertension and maternal hypertension, endogenous $\mathrm{CSE} / \mathrm{H}_{2} \mathrm{~S}$ pathway was downregulated [32, 33]. In our experiment, we also find that $2 \mathrm{~K} 1 \mathrm{C}$ rats exhibit increasing MAP, decreasing plasma level of $\mathrm{H}_{2} \mathrm{~S}$, and downregulated protein expression of CSE. These results suggest that the hypertensive model has been established successfully, and endogenous $\mathrm{CSE} / \mathrm{H}_{2} \mathrm{~S}$ system is downregulated in hypertensive artery. Moreover, NaHS supplement lowers MAP and restores the impairment of $\mathrm{CSE} / \mathrm{H}_{2} \mathrm{~S}$ system. Our results demonstrate that endogenous $\mathrm{CSE} / \mathrm{H}_{2} \mathrm{~S}$ system serves as a critical factor in the pathogenesis of hypertension, which is in accordance with the results of published article [4]. 

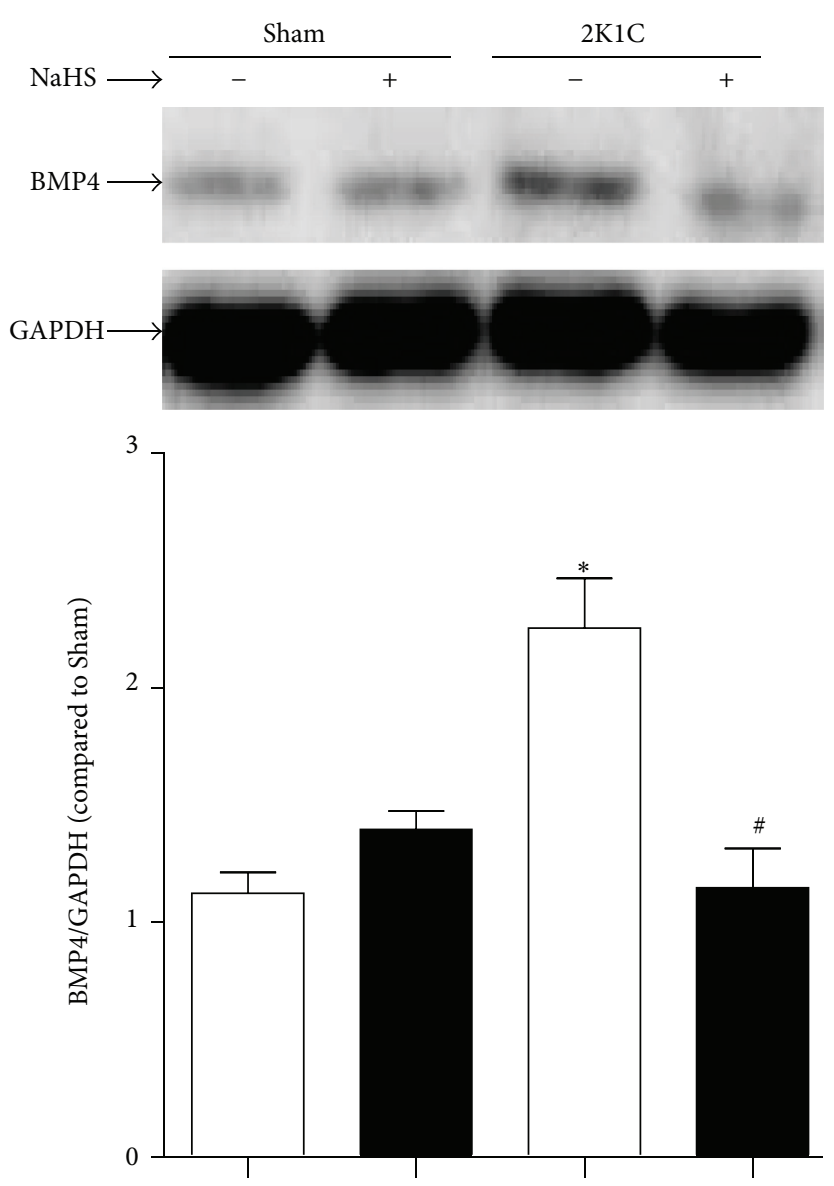

FIGURE 3: Effect of NaHS on protein levels of BMP4 in renal vascular hypertension rats. Data are means \pm SEM. ${ }^{*} P<0.05$ versus Sham; ${ }^{\#} P<0.05$ versus $2 \mathrm{~K} 1 \mathrm{C}$ vehicle. $n=5$ in each group.

Previous studies have demonstrated that impairment of endothelial function is tightly associated with pathogenesis of hypertension $[34,35]$. The damaged endothelium manifested not only the deterioration of endotheliumdependent relaxation, but also the enhancement of the EDCs [24]. Our results show that EDCs was strengthened in renal arteries of $2 \mathrm{~K} 1 \mathrm{C}$ rats, whereas exogenous administration of NaHS reverses the enhanced EDCs in hypertension. These results suggest that $\mathrm{H}_{2} \mathrm{~S}$ may ameliorate endothelial dysfunction and then reduces the elevated blood pressure.

Endothelial dysfunction induced by upregulation of NADPH oxidase and associated increasing oxidative stress has been found in spontaneously hypertensive rats [36, 37]. In experimental models of renovascular hypertension, the increased production of reactive oxygen species (ROS) mediates endothelial dysfunction resulting in progression of renovascular hypertension [38]. In an in vitro oscillatory shear stress (OS) model, it has firstly been confirmed that BMP4 coupled with oxidative stress [39]. A recent study also indicates that BMP4 can increase expression of NADPH oxidase and the level of ROS. These results suggest that BMP4 is a mediator and novel therapeutic target for cardiovascular diseases [40].
The endothelial dysfunction is due to the imbalance of the endothelium-derived relaxing and contracting factors $[41,42]$. COX-2 is an inducible enzyme by inflammatory insult, and then its oxidative conversion of arachidonic acid in ECs results in the formation of an array of prostanoids that contributes to the occurrence of endothelium-dependent contractions $[43,44]$. In renal arteries from hypertensive patients and SHR, BMP4 activates NADPH oxidase, leads to ROS overproduction and upregulation of COX-2 via p38 MAPK-dependent mechanism, which at last increases production of PGF2a, and then strengthens EDCs [24]. All of the above experiments indicated that BMP4/ROS/p38 MAPK/COX-2 pathway was involved in endothelium dysfunction of hypertension.

In our experiment, we find that the protein expressions of BMP4 are increased in hypertensive renal artery. The oxidative stress is accordingly strengthened in hypertension, verified by the increased expression of NADPH oxidase subtype, including NOX2, NOX4, and $\mathrm{p} 67^{\text {phox }}$. Nitrotyrosine is considered as a biomarker for endogenous level of peroxynitrite [45] and has been correlated with elevated levels of other indices of oxidative stress [46]. Malondialdehyde (MDA) is formed in the lipid peroxidation caused by ROS and is also used as a biomarker to measure the level of oxidative stress. 

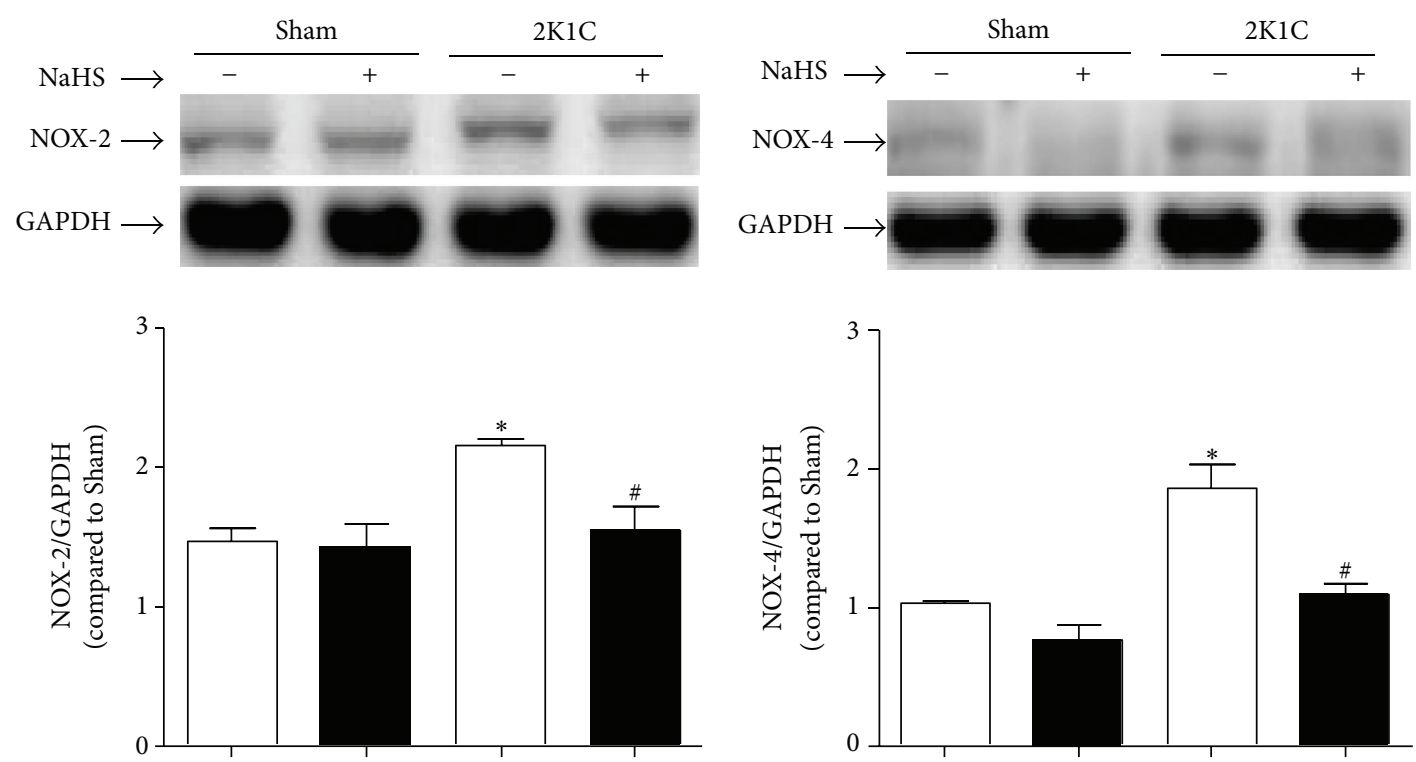

(a)
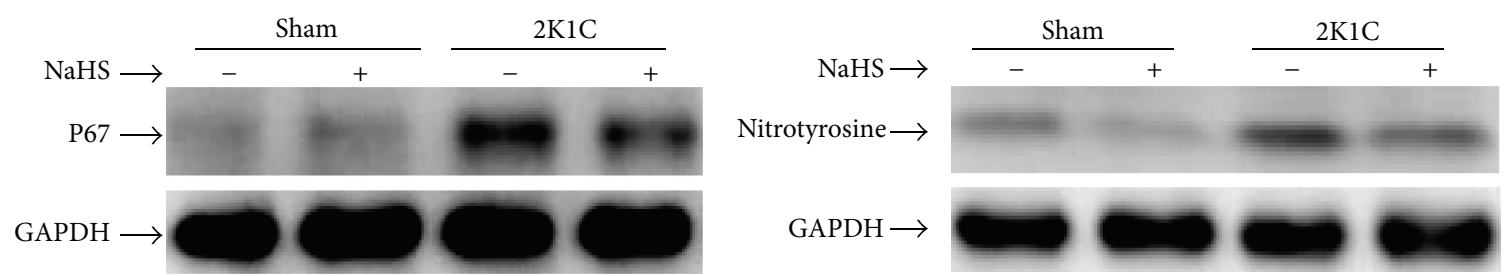

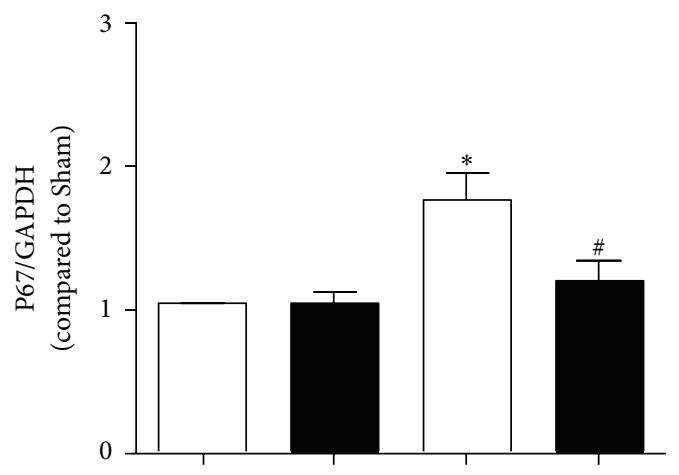

(c)

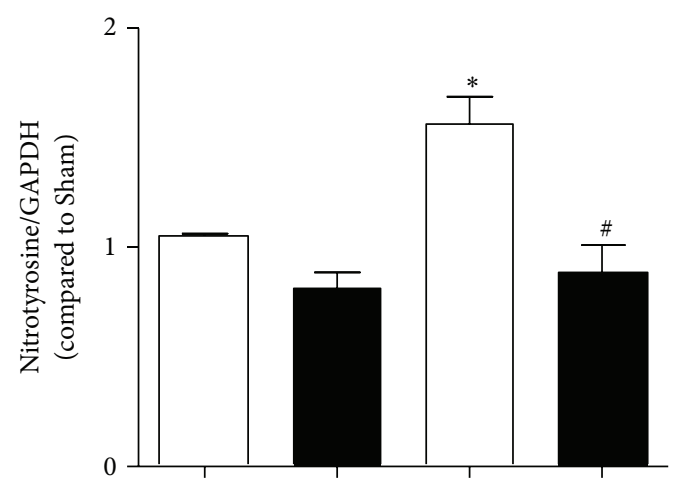

(d)

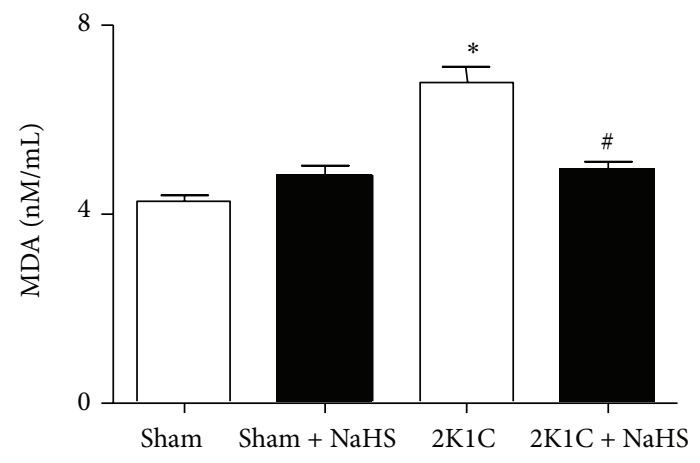

(e)

FIGURE 4: Effect of NaHS on oxidative stress. The oxidative stress was determined by the protein expression of NOX-2 (a), NOX4 (b), P67phox (c), and nitrotyrosine (d) in renal artery and the plasma level of MDA (e). Data are means \pm SEM. ${ }^{*} P<0.05$ versus Sham; ${ }^{\#} P<0.05$ versus $2 \mathrm{~K} 1 \mathrm{C}$ vehicle. $n=5$ in each group for Western blotting; $n=20$ for MDA measurement. 

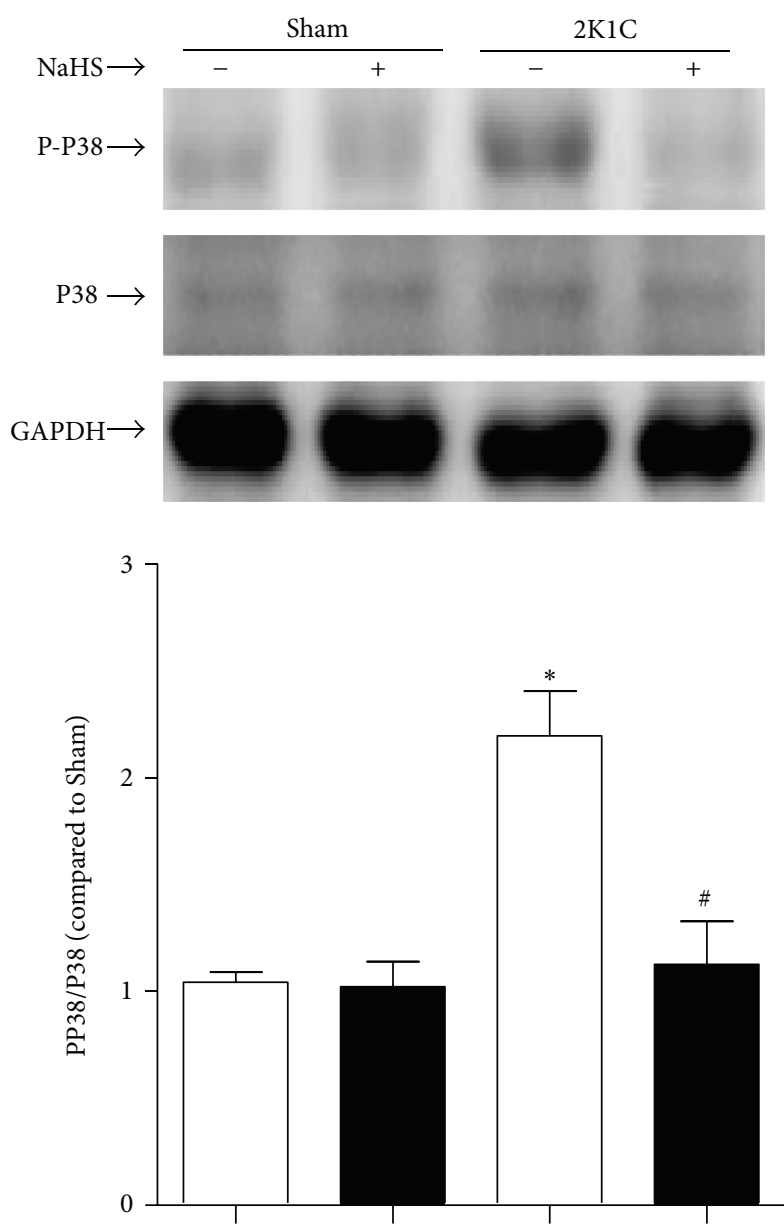

FIGURE 5: Effect of NaHS on the activation of p38 MAPK. Data are means \pm SEM. ${ }^{*} P<0.05$ versus Sham; ${ }^{*} P<0.05$ versus $2 \mathrm{~K} 1 \mathrm{C}$ vehicle. $n=5$ in each group.

As stable marker of oxidative/nitrative stress [47], the expression of nitrotyrosine and the level of MDA elevated in $2 \mathrm{~K} 1 \mathrm{C}$ rats. Otherwise, the phosphorylation level of $\mathrm{p} 38$ MAPK is also increased in hypertensive renal artery. At last, protein expression of COX-2 is elevated in hypertensive renal artery. These results demonstrate that the activation of BMP4/ROS/p38 MAPK/COX-2 pathway involves the pathogenesis of EDCs and hypertension, in accordance with that in other published articles. Moreover, exogenous treatment of NaHS interestingly prevents the activation of the above pathways. These results suggest that protective effect of $\mathrm{H}_{2} \mathrm{~S}$ on endothelium may be mediated by BMP4/ROS/p38 MAPK/COX-2 pathway.

Of course, there are several limits in our study. In our experiment, hypertension was induced by $2 \mathrm{~K} 1 \mathrm{C}$ animal model as previously described [48]. This model was used to mimic hypertension which is characterized by reninangiotensin system (RAS) being excessively activated [49]. The results derived from the present study should be verified in other hypertensive animal models, such as spontaneous hypertension rats. Moreover, we only found the association between $\mathrm{H}_{2} \mathrm{~S}$ and the BMP4/ROS/p38 MAPK/COX-2
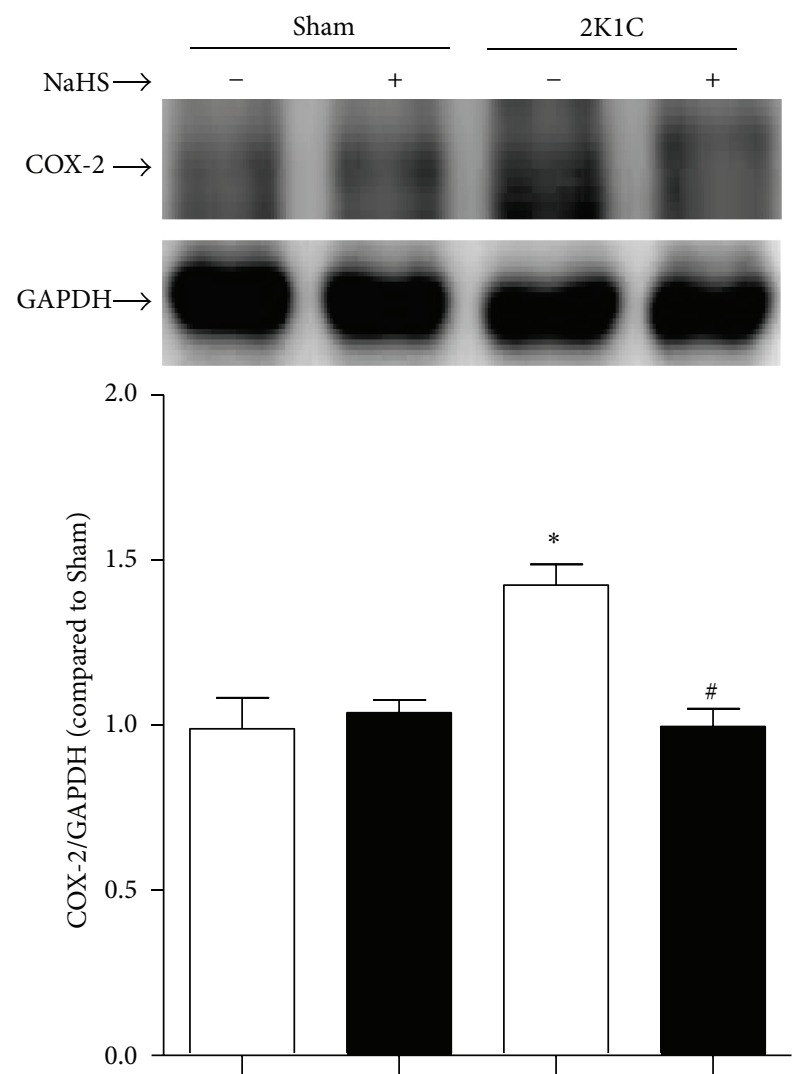

FIGURE 6: Effect of NaHS on protein levels of COX-2. Data are means \pm SEM. ${ }^{*} P<0.05$ versus Sham; ${ }^{*} P<0.05$ versus 2 K1C vehicle. $n=5$ in each group.

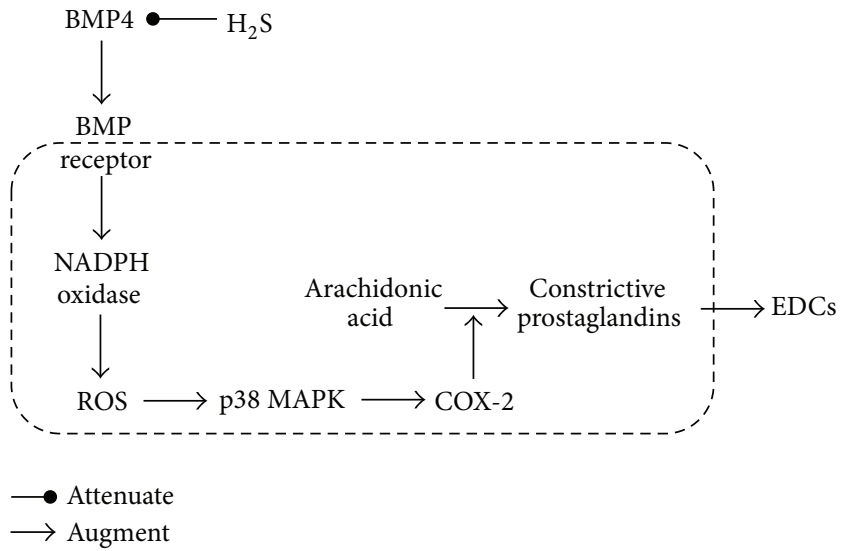

FIGURE 7: Schematic representation of the ameliorative effect of $\mathrm{H}_{2} \mathrm{~S}$ on EDCs.

pathway. The exact mechanism of how $\mathrm{H}_{2} \mathrm{~S}$ regulates the above pathways needs to be further investigated.

\section{Conclusion}

Taken together, our present results demonstrate the inhibitory effect of $\mathrm{H}_{2} \mathrm{~S}$ on BMP4 mediated cellular signaling cascade in hypertension, which may be involved in the 
ameliorative effect of $\mathrm{H}_{2} \mathrm{~S}$ on endothelial dysfunction. Our findings further suggest the potential therapeutic value of $\mathrm{H}_{2} \mathrm{~S}$ for hypertension.

\section{Competing Interests}

The authors declare that there are no competing interests.

\section{Acknowledgments}

This study was supported by the National Natural Science Foundation of China (Grant 31171098), the Specialized Research Fund for the Doctoral Program of Higher Education of China (no. 20121323110008), the Hebei Province for Innovation Talents Support Plan (Grant LJRC017), the Key Medical Guidance Topics of Health Department (20130143), and the office of Education Foundation of Hebei Province of China (QN2016144).

\section{References}

[1] R. Wang, "Two's company, three's a crowd: can $\mathrm{H}_{2} \mathrm{~S}$ be the third endogenous gaseous transmitter?" FASEB Journal, vol. 16, no. 13, pp. 1792-1798, 2002.

[2] N. Shibuya, M. Tanaka, M. Yoshida et al., "3-Mercaptopyruvate sulfurtransferase produces hydrogen sulfide and bound sulfane sulfur in the brain," Antioxidants and Redox Signaling, vol. 11, no. 4, pp. 703-714, 2009.

[3] K. Eto, M. Ogasawara, K. Umemura, Y. Nagai, and H. Kimura, "Hydrogen sulfide is produced in response to neuronal excitation," Journal of Neuroscience, vol. 22, no. 9, pp. 3386-3391, 2002.

[4] G. Yang, L. Wu, B. Jiang et al., " $\mathrm{H}_{2} \mathrm{~S}$ as a physiologic vasorelaxant: hypertension in mice with deletion of cystathionine $\gamma$ lyase," Science, vol. 322, no. 5901, pp. 587-590, 2008.

[5] N. Shibuya, Y. Mikami, Y. Kimura, N. Nagahara, and H. Kimura, "Vascular endothelium expresses 3-mercaptopyruvate sulfurtransferase and produces hydrogen sulfide," Journal of Biochemistry, vol. 146, no. 5, pp. 623-626, 2009.

[6] Y. Sun, C.-S. Tang, J.-B. Du, and H.-F. Jin, "Hydrogen sulfide and vascular relaxation," Chinese Medical Journal, vol. 124, no. 22, pp. 3816-3819, 2011.

[7] M. R. Al-Magableh, B. K. Kemp-Harper, H. H. Ng, A. A. Miller, and J. L. Hart, "Hydrogen sulfide protects endothelial nitric oxide function under conditions of acute oxidative stress in vitro," Naunyn-Schmiedeberg's Archives of Pharmacology, vol. 387, no. 1, pp. 67-74, 2014.

[8] S. Muzaffar, J. Y. Jeremy, A. Sparatore, P. Del Soldato, G. D. Angelini, and N. Shukla, " $\mathrm{H}_{2} \mathrm{~S}$-donating sildenafil (ACS6) inhibits superoxide formation and gp9 ${ }^{\text {phox }}$ expression in arterial endothelial cells: role of protein kinases A and G," British Journal of Pharmacology, vol. 155, no. 7, pp. 984-994, 2008.

[9] Y.-D. Wen, H. Wang, S.-H. Kho et al., "Hydrogen sulfide protects HUVECs against hydrogen peroxide induced mitochondrial dysfunction and oxidative stress," PLoS ONE, vol. 8, no. 2, article e53147, 2013.

[10] K. Suzuki, G. Olah, K. Modis et al., "Hydrogen sulfide replacement therapy protects the vascular endothelium in hyperglycemia by preserving mitochondrial function," Proceedings of the National Academy of Sciences of the United States of America, vol. 108, no. 33, pp. 13829-13834, 2011.
[11] B. L. Predmore, D. Julian, and A. J. Cardounel, "Hydrogen sulfide increases nitric oxide production from endothelial cells by an Akt-dependent mechanism," Frontiers in Physiology, vol. 2, article 104, 2011.

[12] H.-F. Jin, Y. Sun, J.-M. Liang, C.-S. Tang, and J.-B. Du, "Hypotensive effects of hydrogen sulfide via attenuating vascular inflammation in spontaneously hypertensive rats," Zhonghua Xin Xue Guan Bing Za Zhi, vol. 36, no. 6, pp. 541-545, 2008.

[13] D. Chen, M. Zhao, and G. R. Mundy, "Bone morphogenetic proteins," Growth Factors, vol. 22, no. 4, pp. 233-241, 2004.

[14] P. D. Upton, L. Long, R. C. Trembath, and N. W. Morrell, "Functional characterization of bone morphogenetic protein binding sites and Smad1/5 activation in human vascular cells," Molecular Pharmacology, vol. 73, no. 2, pp. 539-552, 2008.

[15] J. Lee, A. Stavropoulos, C. Susin, and U. M. E. Wikesjö, "Periodontal regeneration: focus on growth and differentiation factors," Dental Clinics of North America, vol. 54, no. 1, pp. 93111, 2010.

[16] S. Vukicevic, V. M. Paralkar, N. S. Cunningham, J. S. Gutkind, and A. H. Reddi, "Autoradiographic localization of osteogenin binding sites in cartilage and bone during rat embryonic development," Developmental Biology, vol. 140, no. 1, pp. 209214,1990

[17] Z. S. Haidar, R. C. Hamdy, and M. Tabrizian, "Delivery of recombinant bone morphogenetic proteins for bone regeneration and repair-part A: current challenges in BMP delivery," Biotechnology Letters, vol. 31, no. 12, pp. 1817-1824, 2009.

[18] G. L. Gu, Q. Y. Yang, R. L. Zeng, and X. L. Xu, "The association between BMP4 gene polymorphism and its serum level with the incidence of LVH in hypertensive patients," Journal of Translational Medicine, vol. 13, no. 1, article 14, 2015.

[19] C. R. Dhore, J. P. M. Cleutjens, E. Lutgens et al., "Differential expression of bone matrix regulatory proteins in human atherosclerotic plaques," Arteriosclerosis, Thrombosis, and Vascular Biology, vol. 21, no. 12, pp. 1998-2003, 2001.

[20] K. I. Boström, M. Jumabay, A. Matveyenko, S. B. Nicholas, and Y. Yao, "Activation of vascular bone morphogenetic protein signaling in diabetes mellitus," Circulation Research, vol. 108, no. 4, pp. 446-457, 2011.

[21] S. Miriyala, M. C. G. Nieto, C. Mingone et al., "Bone morphogenic protein-4 induces hypertension in mice: role of noggin, vascular NADPH oxidases, and impaired vasorelaxation," Circulation, vol. 113, no. 24, pp. 2818-2825, 2006.

[22] Y. S. Lau, X. Y. Tian, M. R. Mustafa et al., "Boldine improves endothelial function in diabetic $\mathrm{db} / \mathrm{db}$ mice through inhibition of angiotensin II-mediated BMP4-oxidative stress cascade," British Journal of Pharmacology, vol. 170, no. 6, pp. 1190-1198, 2013.

[23] A. Csiszar, N. Labinskyy, H. Jo, P. Ballabh, and Z. Ungvari, "Differential proinflammatory and prooxidant effects of bone morphogenetic protein-4 in coronary and pulmonary arterial endothelial cells," American Journal of Physiology-Heart and Circulatory Physiology, vol. 295, no. 2, pp. H569-H577, 2008.

[24] W. T. Wong, X. Y. Tian, Y. Chen et al., "Bone morphogenic protein-4 impairs endothelial function through oxidative stress-dependent cyclooxygenase- 2 upregulation: implications on hypertension," Circulation Research, vol. 107, no. 8, pp. $984-$ 991, 2010.

[25] H. Xue, S. Zhou, L. Xiao, Q. Guo, S. Liu, and Y. Wu, "Hydrogen sulfide improves the endothelial dysfunction in renovascular hypertensive rats," Physiological Research, vol. 64, no. 5, pp. 663672, 2015. 
[26] S. L. Wong, F. P. Leung, C. W. Lau et al., "Cyclooxygenase2-derived prostaglandin F $2 \alpha$ mediates endothelium-dependent contractions in the aortae of hamsters with increased impact during aging," Circulation Research, vol. 104, no. 2, pp. 228-235, 2009.

[27] E. H. C. Tang, F. P. Leung, Y. Huang et al., "Calcium and reactive oxygen species increase in endothelial cells in response to releasers of endothelium-derived contracting factor," British Journal of Pharmacology, vol. 151, no. 1, pp. 15-23, 2007.

[28] X. Shen, C. B. Pattillo, S. Pardue, S. C. Bir, R. Wang, and C. G. Kevil, "Measurement of plasma hydrogen sulfide in vivo and in vitro," Free Radical Biology and Medicine, vol. 50, no. 9, pp. 10211031, 2011.

[29] L. G. Navar, L. Zou, A. Von Thun, C. T. Wang, J. D. Imig, and K. D. Mitchell, "Unraveling the mystery of goldblatt hypertension," News in Physiological Sciences, vol. 13, no. 4, pp. 170-176, 1998.

[30] Y. M. Pinto, M. Paul, and D. Ganten, "Lessons from rat models of hypertension: from Goldblatt to genetic engineering," Cardiovascular Research, vol. 39, no. 1, pp. 77-88, 1998.

[31] L. Xiaohui, D. Junbao, S. Lin et al., "Down-regulation of endogenous hydrogen sulfide pathway in pulmonary hypertension and pulmonary vascular structural remodeling induced by high pulmonary blood flow in rats," Circulation Journal, vol. 69, no. 11, pp. 1418-1424, 2005.

[32] C. Zhang, J. Du, D. Bu, H. Yan, X. Tang, and C. Tang, "The regulatory effect of hydrogen sulfide on hypoxic pulmonary hypertension in rats," Biochemical and Biophysical Research Communications, vol. 302, no. 4, pp. 810-816, 2003.

[33] K. Wang, S. Ahmad, M. Cai et al., "Dysregulation of hydrogen sulfide producing enzyme cystathionine $\gamma$-lyase contributes to maternal hypertension and placental abnormalities in preeclampsia," Circulation, vol. 127, no. 25, pp. 2514-2522, 2013.

[34] L. G. Hegde, P. Srivastava, R. Kumari, and M. Dikshit, "Alterations in the vasoreactivity of hypertensive rat aortic rings: role of nitric oxide and superoxide radicals," Clinical and Experimental Hypertension, vol. 20, no. 8, pp. 885-901, 1998.

[35] D. Rizzoni, E. Porteri, M. Castellano et al., "Endothelial dysfunction in hypertension is independent from the etiology and from vascular structure," Hypertension, vol. 31, no. 1, part 2, pp. 335-341, 1998.

[36] K. Wingler, S. Wünsch, R. Kreutz, L. Rothermund, M. Paul, and H. H. H. W. Schmidt, "Upregulation of the vascular NAD $(\mathrm{P}) \mathrm{H}-$ oxidase isoforms Noxl and Nox4 by the renin-angiotensin system in vitro and in vivo," Free Radical Biology and Medicine, vol. 31, no. 11, pp. 1456-1464, 2001.

[37] A. T. Bäumer, C. A. Krüger, J. Falkenberg et al., “The NAD(P)H oxidase inhibitor apocynin improves endothelial NO/superoxide balance and lowers effectively blood pressure in spontaneously hypertensive rats: comparison to calcium channel blockade," Clinical and Experimental Hypertension, vol. 29, no. 5, pp. 287-299, 2007.

[38] L. O. Lerman, K. A. Nath, M. Rodriguez-Porcel et al., "Increased oxidative stress in experimental renovascular hypertension," Hypertension, vol. 37, no. 2, part 2, pp. 541-546, 2001.

[39] G. P. Sorescu, H. Song, S. L. Tressel et al., "Bone morphogenic protein 4 produced in endothelial cells by oscillatory shear stress induces monocyte adhesion by stimulating reactive oxygen species production from a noxl-based NADPH oxidase," Circulation Research, vol. 95, no. 8, pp. 773-779, 2004.
[40] B. Sun, R. Huo, Y. Sheng et al., "Bone morphogenetic protein-4 mediates cardiac hypertrophy, apoptosis, and fibrosis in experimentally pathological cardiac hypertrophy," Hypertension, vol. 61, no. 2, pp. 352-360, 2013.

[41] S. Taddei, A. Virdis, L. Ghiadoni, I. Sudano, and A. Salvetti, "Effects of antihypertensive drugs on endothelial dysfunction: clinical implications," Drugs, vol. 62, no. 2, pp. 265-284, 2002.

[42] E. L. Schiffrin, "Role of endothelin-1 in hypertension and vascular disease," American Journal of Hypertension, vol. 14, no. 6, part 2, pp. 83S-89S, 2001.

[43] D. Yang, M. Félétou, C. M. Boulanger et al., "Oxygen-derived free radicals mediate endothelium-dependent contractions to acetylcholine in aortas from spontaneously hypertensive rats," British Journal of Pharmacology, vol. 136, no. 1, pp. 104-110, 2002.

[44] Z. Bagi, N. Erdei, A. Toth et al., "Type 2 diabetic mice have increased arteriolar tone and blood pressure: enhanced release of COX-2-derived constrictor prostaglandins," Arteriosclerosis, Thrombosis, and Vascular Biology, vol. 25, no. 8, pp. 1610-1616, 2005.

[45] H. Ahsan, "3-Nitrotyrosine: a biomarker of nitrogen free radical species modified proteins in systemic autoimmunogenic conditions," Human Immunology, vol. 74, no. 10, pp. 1392-1399, 2013.

[46] H. Ischiropoulos, "Biological tyrosine nitration: a pathophysiological function of nitric oxide and reactive oxygen species," Archives of Biochemistry and Biophysics, vol. 356, no. 1, pp. 1-11, 1998.

[47] C. Herce-Pagliai, S. Kotecha, and D. E. G. Shuker, "Analytical methods for 3-nitrotyrosine as a marker of exposure to reactive nitrogen species: a review," Nitric Oxide, vol. 2, no. 5, pp. 324336, 1998.

[48] G. Ferretti, A. Salomone, P. L. Castagno, P. Miglietti, and P. Rispoli, "Renovascular hypertension: a non-invasive Duplex Scanning screening," International Angiology, vol. 7, no. 3, pp. 219-223, 1988.

[49] C. V. S. Ram, "Renovascular hypertension," Cardiology Clinics, vol. 6, no. 4, pp. 483-508, 1988. 


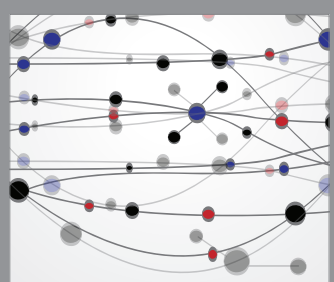

The Scientific World Journal
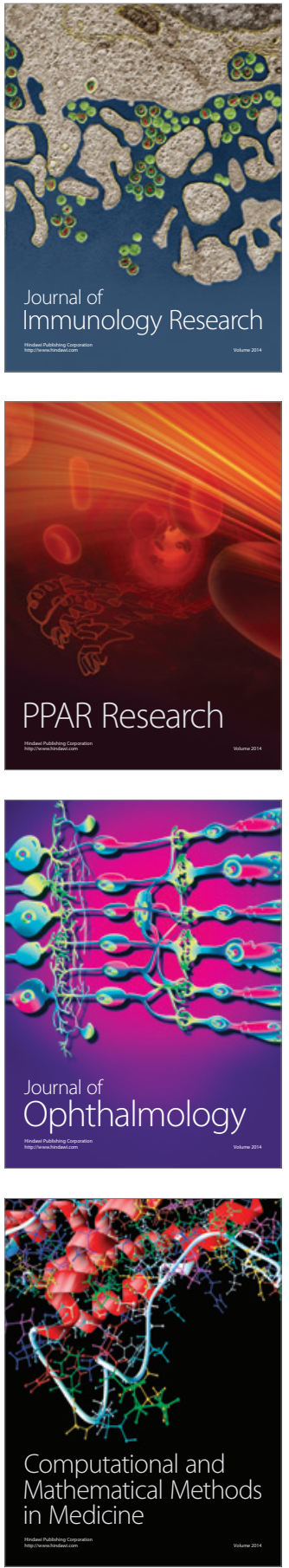

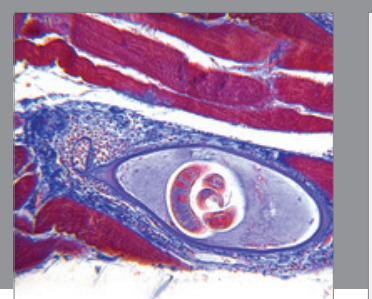

Gastroenterology Research and Practice

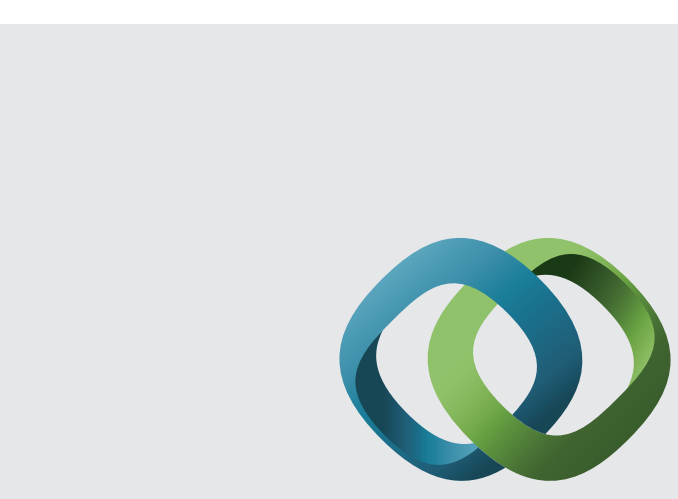

\section{Hindawi}

Submit your manuscripts at

http://www.hindawi.com
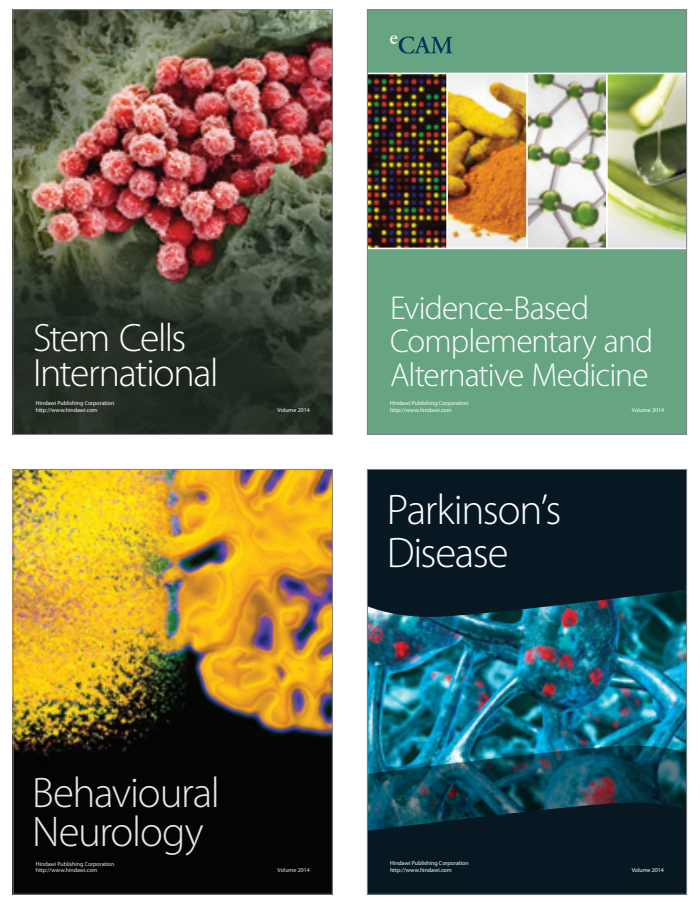
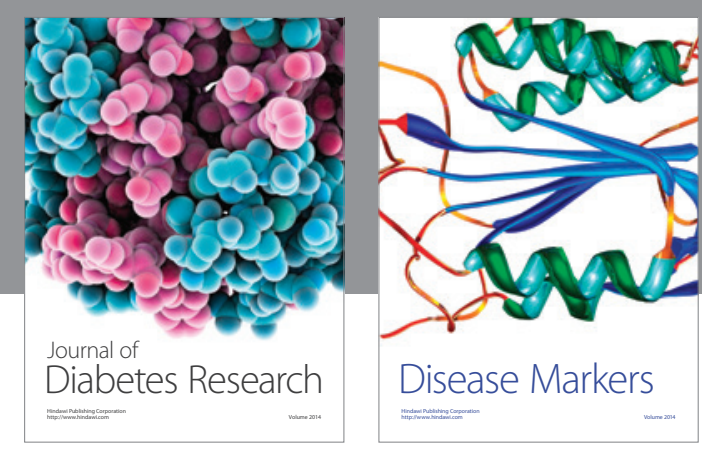

Disease Markers
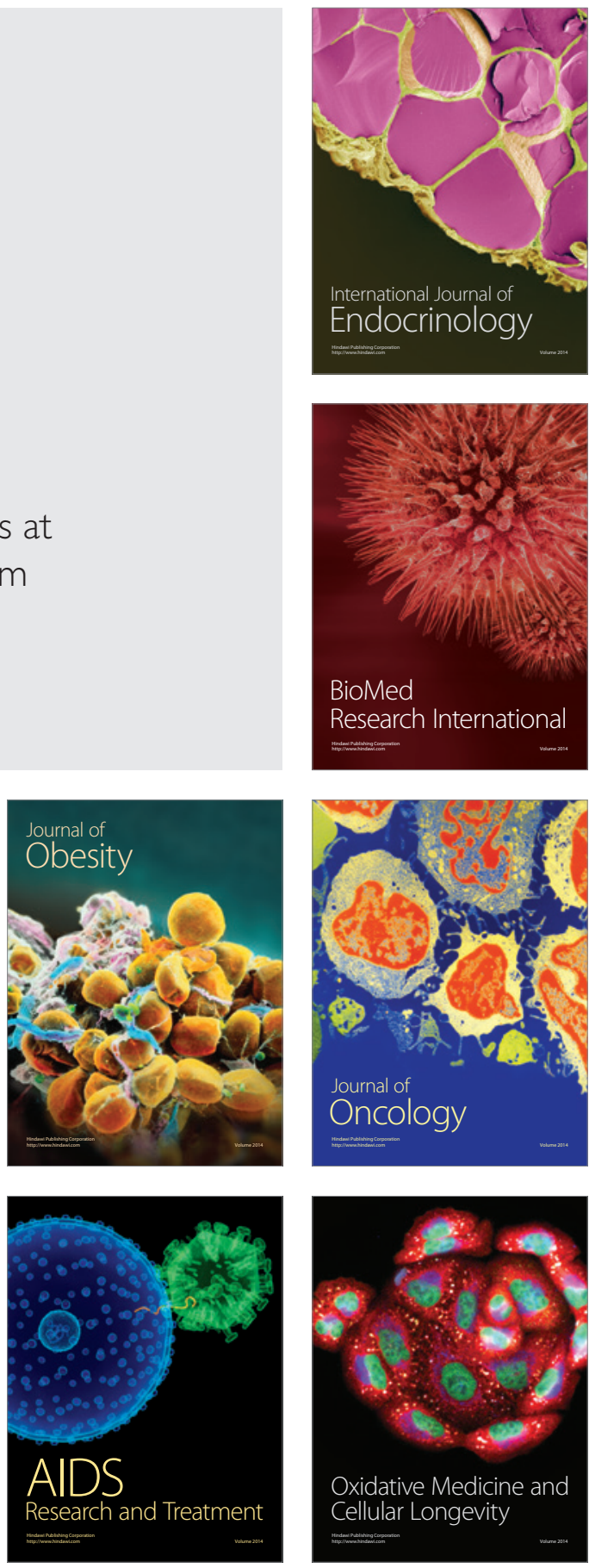